\title{
QUÉ HACER Y A QUIÉN DENUNCIAR SI SE ES VICTIMA DE UNA IRREGULARIDAD O FRAUDE: ALGUNOS TIPS'
}

\author{
Christian M. Nino-Moris \\ Profesor de Auditoria Forense, Universidad Alberto Hurtado
}

\begin{abstract}
Resumen
Este artículo aborda la problemática de cómo enfrentar alguna conducta fraudulenta, o irregular, dentro de una organización. El entendimiento de una irregularidad exige conocer en que entorno se mueve la entidad y sus características de Gobierno Corporativo, a saber: ¿de qué tipo de entidad se trata, público o privado?; Si es privado: ¿es una entidad regulada o no por algún Servicio supervisor?; ¿quién está involucrado en dicha irregularidad: un empleado o un alto directivo? Se proponen los caminos a seguir en cada una de estas situaciones y se considera el rol de los auditores externos.
\end{abstract}

Máxima del Derecho: El Estado sólo puede hacer o dejar de hacer lo que la ley le permita y mande. A contrario sensu, los privados pueden hacer todo aquello que no infrinja la ley. Dicho de otro modo, todo lo que no está prohibido está permitido.

\section{Revisión de algunas estadísticas}

De acuerdo con algunas de las estadísticas publicadas por la Association of Certified Fraud Examiners (ACFE) en su "Report of the Nations" del año 2014, se reveló que:

- El $42 \%$ de los fraudes en las organizaciones son cometidos por los propios empleados;

- Un 67\% de los defraudadores son hombres;

- Un $17.4 \%$ de las irregularidades detectadas provienen del departamento de contabilidad;

- Dos años toma en promedio en ser detectado un fraude de es tados financieros;

- El 42\% de los fraudes son detectados "por soplo" (es decir, no por las auditorías que se practican);

- El 49\% de los casos reportados son denunciados por los propios empleados;

- Un 32\% de los casos reportados se produjeron por la falta de controles internos;

- El 18.1\% de los defraudadores tenían una edad promedio de 43 años, pero increíblemente la mayor pérdida promedio fue para aquellos con edad por sobre los 60 años (mayor experiencia laboral);

- El tiempo de permanencia de los victimarios (con contrato) antes de cometer un fraude fue de 1 a 5 años de antigüedad, los cuales poseían mayoritariamente un posgrado académico;

- El 43.8\% de los defraudadores cometió fraude motivados por llevar un estilo de vida más allá de sus medios;

- Un 33\% lo hacían por tener algún tipo de dificultad financiera.

Al ser las estadísticas expuestas claras y reveladoras, conviene preguntarse ¿qué se entiende por fraude? En Chile el término fraude no está definido en nuestra legislación. Sin embargo, lo que sí se define es qué es "delito". Nuestro Código Penal en su artículo primero define delito como toda acción u omisión voluntaria penada por la ley. Ahora bien, de acuerdo al o a los bienes jurídicos que se protegen, los delitos pueden ser delitos contra la propiedad, tributario, contable-financiero u otro que esté en la esfera de los llamados "delitos económicos". A este respecto, la ley tampoco se refiere a la figura de delito económico; no obstante, la jurisprudencia y las prácticas de los negocios han entendido estos delitos como, a juicio del jurista español Miguel Bajo Fernández, la infracción jurídico-penal que lesiona o pone en peligro el orden económico entendido como regulación jurídica del intervencionismo estatal en la Economía de un país.

\section{Configuración de los fraudes}

Pues bien, ¿qué es un fraude? Según la Real Academia Española de la Lengua (RAE) fraude puede ser definido como un acto tendente a eludir una disposición legal en perjuicio del Estado o de terceros. Una definición más profesional la encontramos en las Normas de Auditoría Interna y de Gestión la que define fraude como cualquier acto ilegal caracterizado por engaño, ocultación o violación de confianza. Estos fraudes son perpetrados sin violencia física por individuos o por organizaciones para apropiarse en forma indebida de dinero, bienes o servicios, para evitar pagos o pérdidas de servicios o para asegurarse ventajas personales o de negocio. En tanto la ACFE ha definido fraude (ocupacional) como el uso de la ocupación profesional para el enriquecimiento personal a través del abuso intencional o uso indebido de los recursos o activos de la empresa. 


\section{Tipología de los Fraudes}

Los fraudes pueden clasificarse siguiendo algunos de estos patrones (propuesta del autor del artículo):

\begin{tabular}{|c|c|}
\hline \multirow{2}{*}{ Según quién los perpetra } & - Fraude Corporativo (Administración, Alta Dirección Pública, Consejo Superior, etc.) \\
\hline & - Fraude Laboral (empleados públicos o privados) \\
\hline \multirow{2}{*}{ Según la naturaleza jurídica de la organización involucrada } & - Entidad Pública (incluye las municipalidades) \\
\hline & - Entidad Privada (incluye organizaciones con o sin fines de lucro) \\
\hline \multirow{8}{*}{ Según la naturaleza del fraude o irregularidad } & - Fraude electrónico (scams, emails, Internet) \\
\hline & - Fraude tributario (incluye infracciones) \\
\hline & - Fraude por quiebra fraudulenta \\
\hline & - Fraude servicios financieros \\
\hline & - Fraude laboral \\
\hline & - Fraude contable-financiero \\
\hline & - Delitos contra la libre competencia \\
\hline & - Abuso laboral (uso inadecuado de los recursos de una entidad) \\
\hline \multirow{3}{*}{ Según la supervisión ejercida sobre la entidad involucrada } & - Entidad bajo un Servicio o Superintendencia \\
\hline & - Entidades sin fines de lucro (Ministerio de Justicia) \\
\hline & - Entidad sin supervisión directa \\
\hline \multirow{3}{*}{ Según a qué personas afectan } & - Personas naturales \\
\hline & - Personas jurídicas en general \\
\hline & - Empresas e instituciones del Estado \\
\hline
\end{tabular}

\section{¿Cuándo un fraude es delito?}

Un fraude es delito cuando el fraude está específicamente establecido en una norma (tipo) penal, estableciendo (y describiendo) la conducta penada y la sanción asociada al delito. Pero aun así, no sólo bastará comparar si el hecho se adapta la descripción del delito, sino que habrá que hacer también un análisis de culpabilidad (dolo o culpa), y de antijuridicidad (causales que pudieran eximir de responsabilidad penal) a fin de poder imponer una pena.

\section{Qué, cómo, cuándo y dónde denunciar un fraude o irregularidad}

Sin entrar por ahora en una distinción técnica, en general irregularidad y fraude son considerados actos dolosos. Así entonces, la pregunta recurrente es (o que debiese ser) ¿qué hacer si soy víctima de un delito económico o tengo conocimiento de un fraude o irregularidad? La respuesta no es lineal ni dicotómica, aunque si es algo algorítmica. Eso dependerá, como lo hemos ya expuesto, de qué fraude o irregularidad se trate; qué tipo de organización es o está involucrada; cuál es posición jerárquica del infractor; qué canal de denuncia se dispone; o si es una empresa bajo regulación de algún servicio público o superintendencia, etc.
Es largo y complejo de identificar todos los escenarios posibles, pero lo más acertado es partir diciendo lo que no se debe hacer en una primera instancia. Aunque parezca de Perogrullo, lo primero es no perder la calma, especialmente si es el jefe, algún compañero de trabajo o alguien conocido quien está involucrado. Lo segundo, es no actuar emocionalmente. Cerciorarse de reunir la mayor cantidad de información posible para confirmar las sospechas, o la naturaleza fáctica de que se fue o se es testigo. Tercero, no comentar con nadie respecto a la información que se maneja. El hacerlo pondría en riesgo la investigación interna administrativa que se llevaría a cabo (por ejemplo, según la metodología de respuesta que disponga la unidad de auditoría interna). Es importante también que se busque ayuda en el círculo de confianza más inmediato, pero que este fuera de la arena laboral; fuera incluso del ámbito profesional. Por último, tener presente que el secreto profesional, si procediere, no significa "callar ciegamente" sobre las operaciones irregulares de una empresa y de sus propietarios, por ejemplo. El deber de informar un acto delictual o las sospechas fundadas de él está por sobre dicho secreto, especialmente cuando se trata de la prevención de consecuencias graves al bien común. Si es del caso, se debe recurrir a un abogado para recibir orientación profesional para proteger tanto al denunciante como a la información o evidencia que sea posea, o en donde ésta se hallase (custodia). 


\section{Sobre el procedimiento de denuncia}

Por regla general, el sentido común podría llevarnos a entablar una denuncia ante la Fiscalía (Carabineros, o PDI) sobre lo que sabemos. Sin embargo, para llegar a esa instancia deben de satisfacerse otros canales, si es que existen o están disponibles en las organizaciones para hacer una denuncia. Si no hay otro camino, se debería recurrir a la Fiscalía, recuerde que deberá identificarse, por cuanto las denuncias anónimas in-situ no son acogidas; sin embargo, a partir del año 2014, la Fiscalía acoge a tramitación y seguimiento las denuncias anónimas producto de un Acuerdo suscrito con el Ministerio del Interior.

Veamos algunas situaciones concretas que pueden ser útiles de identificar.

\section{Acción institucional pública y privada}

Hoy en día es muy común que las instituciones, sean públicas, privadas, con o sin fines de lucro, posean canales de denuncia abierto tanto al público (clientes) como para sus empleados/ funcionarios. Si se trata de una institución o servicio de carácter público lo más probable es que esa institución cuente con los instrumentos legales y reglamentarios para canalizar las denuncias por fraudes o irregularidades que reciban de la ciudadanía o de los propios funcionarios, quienes además, son protegidos por denunciar irregularidades y faltas al principio de probidad administrativa regulado por la ley sobre Bases Generales de la Administración del Estado (Ley 20205/2007).

Por regla general, y en el contexto de este artículo, existen tres grandes instituciones estatales encargadas de resguardar los intereses patrimoniales-económicos de las personas (naturales y jurídicas, sean estas últimas de derecho público o privado) de manera centralizada y que son: La Contraloría General de la República (CGR), el Consejo de Defensa del Estado (CDE), y el Ministerio Público (Fiscalía).

Como bien lo indica la página institucional de la CGR, ésta recibe denuncias de uno o más hechos puntuales, relacionados con una eventual situación irregular, cometida por un funcionario o servicio sometido a su fiscalización, con el objetivo que se investigue y determine la veracidad de lo expuesto y las responsabilidades que de ello puedan derivarse. El campo de acción fiscalizadora de la CGR es como sigue:

- Servicios públicos centralizados (Ministerios, Intendencias, Gobernaciones, Tesorería General, ONEMI, Fuerzas Armadas y de Orden y Seguridad, entre otros);
- Servicios públicos descentralizados (de Salud, de Vivienda y Urbanismo, Universidades Estatales, Impuestos Internos, Previsión Social, FONASA, SENCE, JUNAEB, JUNJI, entre otros);

- Todas las municipalidades del país;

- Empresas públicas creadas por ley (ENAP, ENAMI, FAMAE, ENAER, ASMAR, Empresas Portuarias, entre otras);

- Empresas, sociedades o entidades públicas y privadas en que el Estado o sus empresas, sociedades o instituciones centralizadas o descentralizadas tengan aportes de capital (Metro, SERCOTEC, CONAF, entre otras).

La inmensa mayoría de estas instituciones posee canales de denuncia en línea, por teléfono, email, y según corresponda, una intranet para tales propósitos.

Por su parte el CDE, y como bien lo señala su portal institucional, es la institución pública de Chile que asesora, defiende y representa los intereses patrimoniales y no patrimoniales del Estado de Chile y sus Organismos, tanto a través del ejercicio de acciones y defensas judiciales como extrajudiciales. Digamos en términos simples y coloquiales que es el "abogado del papá Fisco".

En lo que se refiere a la Fiscalía, su misión entre otras, consiste en realizar todas aquellas acciones tendientes a dirigir en forma exclusiva la investigación de las causas criminales que la ciudadanía denuncie, o que de oficio pueda iniciar y ejercer, en definitiva, la acción penal pública. En relación al Estado, su función es la de investigar todas aquellos delitos que comprometa la probidad funcionaria, el patrimonio fiscal o el de órganos estatales, o en que hayan participado funcionarios públicos en el desempeño de sus funciones.

\section{Acción individual: Cuando un ciudadano es víctima de un fraude}

De acuerdo con nuestro Código Procesal Penal cualquier persona podrá comunicar directamente a la Fiscalía el conocimiento que tuviere de la comisión de un hecho que revistiere características de delito. Alternativamente la ley entrega la posibilidad de denunciar ante los funcionarios de Carabineros de Chile, de la Policía de Investigaciones, o ante cualquier tribunal con competencia criminal, los que a su vez deberán hacer llegar la denuncia a la Fiscalía. Los plazos para presentar una denuncia dicen relación con los plazos de prescripción asociados al potencial delito.

No obstante, como ya se ha mencionado, existen canales previos que ofrecen los organismos públicos y privados para facilitar tanto el cumplimiento de la ley como la acción misma de la denuncia. Aquí un resumen sucinto al respecto: 


\begin{tabular}{|c|c|c|c|c|}
\hline INSTITUCIÓN & $\begin{array}{l}\text { MATERIA DE DENUNCIA } \\
\text { (FRAUDE O IRREGULARIDAD) }\end{array}$ & $\begin{array}{l}\text { EJEMPLOS } \\
\text { DELITO ECONÓMICO }\end{array}$ & $\begin{array}{l}\text { DENUNCIA } \\
\text { ONLINE }\end{array}$ & SITIO WEB \\
\hline $\begin{array}{l}\text { Servicio de Impuestos } \\
\text { Internos }\end{array}$ & $\begin{array}{l}\text { Se refiere a contribuyentes que } \\
\text { practican conductas, mediante las } \\
\text { cuales omiten o sub-declaran sus } \\
\text { impuestos, distorsionan o alteran su } \\
\text { situación tributaria en perjuicio del } \\
\text { interés fiscal. }\end{array}$ & $\begin{array}{l}\text { Emisión facturas falsas; } \\
\text { no pago de impuestos, } \\
\text { declaraciones de impuestos } \\
\text { maliciosamente falsas, etc. }\end{array}$ & SI & www.sii.cl \\
\hline $\begin{array}{l}\text { Superintendencia de Valores } \\
\text { y Seguros }\end{array}$ & $\begin{array}{l}\text { Acoge reclamos o denuncias ya sea } \\
\text { en contra de entidades de seguros, } \\
\text { o en contra de entidades de valores, } \\
\text { entre otras. }\end{array}$ & $\begin{array}{l}\text { Uso información privilegiada; } \\
\text { emisión de valores empresas } \\
\text { en insolvencia; reclamos de } \\
\text { seguros con datos falsos. }\end{array}$ & $\mathrm{SI}$ & www.svs.cl \\
\hline $\begin{array}{l}\text { Superintendencia de Bancos } \\
\text { e Instituciones Financieras }\end{array}$ & $\begin{array}{l}\text { Acoge las denuncias de cualquier } \\
\text { organismo público o privado, que } \\
\text { tome conocimiento de alguna } \\
\text { infracción sobre ejercicio ilegal del } \\
\text { giro bancario, o abusos cometidos } \\
\text { por los bancos en instituciones } \\
\text { financieras. }\end{array}$ & $\begin{array}{l}\text { Usura y cobros excesivos; } \\
\text { operación de financieras } \\
\text { ilegales. }\end{array}$ & $\mathrm{SI}$ & www.sbif.cl \\
\hline Dirección del Trabajo & $\begin{array}{l}\text { Acoge denuncias o reclamos } \\
\text { indistintamente si la relación laboral } \\
\text { está vigente o concluida, sobre } \\
\text { el cumplimiento de las normas } \\
\text { laborales, previsionales, y de higiene } \\
\text { y seguridad en el trabajo. }\end{array}$ & $\begin{array}{l}\text { No pago de cotizaciones } \\
\text { previsionales; } \\
\text { No pago de indemnizaciones } \\
\text { por ley; No reconocimiento de } \\
\text { los derechos salariales, etc. }\end{array}$ & $\mathrm{SI}$ & www.dt.gob.cl \\
\hline $\begin{array}{l}\text { Superintendencia de } \\
\text { Pensiones }\end{array}$ & $\begin{array}{l}\text { Acoge consultas y reclamos que } \\
\text { pueden abarcar áreas referidas al } \\
\text { sistema previsional vigente y al } \\
\text { Seguro de Cesantía. }\end{array}$ & $\begin{array}{l}\text { No pago de cotizaciones } \\
\text { previsionales. }\end{array}$ & SI & www.safp.cl \\
\hline SERNAC & $\begin{array}{l}\text { Acoge el reclamo de los } \\
\text { consumidores y denuncia ante } \\
\text { la justicia a las empresas que } \\
\text { atropellan sus derechos para } \\
\text { que reciban sanción y para exigir } \\
\text { indemnizaciones por los daños } \\
\text { causados. }\end{array}$ & $\begin{array}{l}\text { Cobros tarjetas de crédito; } \\
\text { estafas por internet; abusos } \\
\text { empresas del retail, cláusulas } \\
\text { abusivas, etc. }\end{array}$ & $\mathrm{SI}$ & www.sernac.cl \\
\hline Fiscalía Nacional Económica & $\begin{array}{l}\text { Investiga todo hecho acto o } \\
\text { convención que impida, restrinja o } \\
\text { entorpezca la libre competencia en } \\
\text { los mercados, o tienda a producir } \\
\text { tales efectos, denunciando ante } \\
\text { el Tribunal de Defensa de la Libre } \\
\text { Competencia los ilícitos que } \\
\text { configuren esas conductas. }\end{array}$ & $\begin{array}{l}\text { Actividades monopólicas; } \\
\text { carteles por colusión de } \\
\text { precios. }\end{array}$ & SI & www.fne.cl \\
\hline Colegio Profesionales, etc. & $\begin{array}{l}\text { Tramitación de acusaciones o } \\
\text { denuncias por Infracción a las } \\
\text { normas sobre el ejercicio de una } \\
\text { profesión y la ética. }\end{array}$ & $\begin{array}{l}\text { Profesionales colegiados } \\
\text { denunciados por estafa por sus } \\
\text { clientes. }\end{array}$ & NO & $\begin{array}{l}\text { Sitio web según de la } \\
\text { profesión de que se trate }\end{array}$ \\
\hline $\begin{array}{l}\text { Sistema Integral de Atención } \\
\text { Ciudadana (SIAC)/ OIRS }\end{array}$ & $\begin{array}{l}\text { Realización, entre otros, de consultas } \\
\text { y reclamos que la ciudadanía } \\
\text { canalice. }\end{array}$ & $\begin{array}{l}\text { Cualquier tipo de reclamo } \\
\text { o denuncia en la esfera de } \\
\text { la Administración Pública- } \\
\text { ciudadana. }\end{array}$ & $\mathrm{SI}$ & $\begin{array}{l}\text { SIAC/OIRS es } \\
\text { incorporado como } \\
\text { links complementario } \\
\text { a los sitios webs } \\
\text { gubernamentales }\end{array}$ \\
\hline Denuncia Seguro & $\begin{array}{l}\text { El principal compromiso de este } \\
\text { programa es el anonimato de las } \\
\text { personas que llaman para denunciar. }\end{array}$ & $\begin{array}{l}\text { Antecedentes de delitos contra } \\
\text { la propiedad intelectual e } \\
\text { industrial, entre otros. }\end{array}$ & $\begin{array}{c}\text { NO, solo } \\
\text { numero } 600\end{array}$ & www.denunciaseguro.cl \\
\hline
\end{tabular}


El principio básico es entablar la denuncia directamente en la repartición pública o empresa privada encargada de acoger la denuncia. Suponiendo que esa institución sea una Superintendencia quien acoge la denuncia, hay que previamente asegurarse que se haya agotado la instancia previa de reclamo ante la entidad que está bajo la supervisión de esa superintendencia (es decir, seguir y agotar el conducto regular). Por ejemplo, si Ud. detecta una irregularidad con el manejo de una póliza de seguros, deberá previamente hacer su reclamo ante la aseguradora; si no existe respuesta de parte de la entidad, recién se podrá hacer la denuncia ante la Superintendencia respectiva, esto es, la Superintendencia de Valores y Seguros (SVS). Si se omite este paso, lo más probable que sea la propia SVS quien indique que se resuelva la situación siguiendo el conducto regular fijado por su regulado. A su turno, si es la entidad aseguradora quien detecta que sus asegurados son quienes están cometiendo fraude o alguna irregularidad, será ésta quien, por medio de su asesor legal, evalúe los pasos a seguir para perseguir a los responsables interponiendo una denuncia o presentando una querella criminal.

\section{Acción individual: Cuando un funcionario público detecta un fraude}

$\mathrm{Si}$ es un funcionario público quien detecta un fraude o irregularidad, éste deberá ceñirse a las políticas y procedimientos legales que su institución cuenta. La ley establece claramente que el funcionario público debe denunciar los delitos de que tomaren conocimiento en el ejercicio de sus funciones $y$, especialmente, en su caso, los que notaren en la conducta ministerial de sus subalternos. (Artículo 175 CPP). Dichos funcionarios, deberán hacer la denuncia dentro de las veinticuatro horas siguientes al momento en que tomaren conocimiento del hecho criminal ${ }^{2}$.

\section{Qué hacer: ¿Reclamo, denuncia o querella?}

A modo de corolario, un fraude o irregularidad puede conllevar las siguientes acciones administrativas $\mathrm{y} / \mathrm{o}$ legales:

a. Un simple reclamo o constancia: Es una instancia simple, que más bien resulta ser un procedimiento administrativo muy sencillo. Muchas instituciones poseen una plataforma web para canalizar los reclamos de sus clientes y consumidores. La naturaleza de un reclamo dice relación con el cumplimiento de expectativas entidad-cliente, como por ejemplo fallas o desperfectos de un producto, ausencia de garantías, etc.

b. Una denuncia: Es la forma de dar inicio a una investigación penal, al informar a la autoridad un hecho que constituye un delito, pudiendo efectuarse en forma verbal o por escrito y debe contener la identificación del denunciante, su domicilio, la narración del hecho, la eventual designación del autor y de los testigos. Esta instancia es más bien pre-judicial. Es inicialmente un procedimiento administrativo que se lleva a cabo en la Fiscalía o policías que tiene jurisdicción en el domicilio del denunciante. Según el último informe estadístico de la Fiscalía, las denuncias por uso fraudulento de tarjetas de crédito y débito fueron las más recurrentes.

El Código Procesal Penal establece que la denuncia podrá formularse por cualquier medio y deberá contener:

1. La identificación del denunciante;

2. Domicilio;

3. La narración del hecho;

4. La designación de quienes lo hubieren cometido y de las personas que lo hubieren presenciado o que tuvieren noticia de él, todo en cuanto le constare al denunciante;

5. En el caso de la denuncia verbal se levantará un registro en presencia del denunciante, quien lo firmará junto con el funcionario que la recibiere;

6. La denuncia escrita será firmada por el denunciante. Si el denunciante no pudiere firmar, lo hará un tercero habilitado para ello.

Tal como lo indican las instrucciones de la Fiscalía, el fiscal a cargo deberá evaluar la posibilidad y necesidad de realizar diligencias preliminares $\mathrm{y} / \mathrm{o}$ de despachar una orden de investigar, en atención a la probabilidad de obtener algún resultado exitoso para el esclarecimiento de los hechos o la individualización de los involucrados. Note que el hecho de la denuncia no significa la imputación de un delito. Una denuncia es la puesta en conocimiento a las autoridades competentes sobre la naturaleza de un hecho que puede afectar el interés social. Sin embargo, ella no puede ser infundada, pudiendo configurarse por este hecho, un delito de denuncia calumniosa.

c. Una querella: La querella es la acción que entabla la víctima del delito, según un orden de prelación expresamente establecido y requiere el patrocinio de un abogado. Sin embargo, para el caso de los órganos y servicios públicos sólo podrán interponer querella cuando sus respectivas leyes orgánicas les otorguen expresamente las potestades correspondientes. De acuerdo con nuestro Código Procesal Penal la querella podrá presentarse en cualquier momento, mientras el fiscal no

(2) Respecto a las normas sobre lavado de dinero, la reciente Ley 20818, establece que "el funcionario público que, en razón de su cargo, tome conocimiento de alguno de los delitos contemplados en los artículos 60, 70, 13 y 31 de esta ley y omita denunciarlo al Ministerio Público, a los funcionarios de Carabineros de Chile o de la Policía de Investigaciones, o ante cualquier tribunal con competencia en lo criminal, será castigado con presidio menor en sus grados medio a máximo y multa de cuarenta a cuatrocientas unidades tributarias mensuales." 
declarare cerrada la investigación, debiendo someterse a un examen de admisibilidad ante el juez de garantía. El objetivo principal de una querella será lograr el esclarecimiento del delito y la sanción de sus responsables, adicionalmente podrá obtenerse la reparación de un daño infligido a la víctima. La principal diferencia entre la denuncia y la querella, es que al querellante se le otorga el derecho de intervenir en el proceso penal, solicitando diligencias, interponiendo recursos e incluso llevando adelante la acusación cuando el Ministerio Públicio ha decidido no perseverar en la investigación.

\section{¿Cómplice o Víctima de un fraude o irregularidad?: Depende.}

Por regla general, nuestro Código Penal sanciona con reclusión menor tanto el funcionario público como a las personas que ejerzan una profesión con un título (profesionales del sector privado) por la revelación de los secretos que en el ejercicio de sus cargos se les hubieren confiado. Sin embargo, el escenario es completamente diferente si tales personas tienen conocimiento de un hecho irregular. Aquí los efectos son distintos. Por ejemplo, si un empleador "invita" a un trabajador a participar en conductas irregulares, o al menos reprochables, ese trabajador debería ponerlo en conocimiento de la empresa (siguiendo el conducto regular fijado, si existiese) y no ser parte de tales conductas a objeto de evitar convertirse en cómplice. Hacerse parte no solo significaría una causal de despido, sino además de ser perseguido civil y/o criminalmente. Sin embargo, si el trabajador se ve expuesto a exigencias que no le impone el contrato de trabajo o éstas son contrarias a las normas internas de la empresa, el trabajo puede invocar el auto-despido en los términos que prescribe el Código del Trabajo, el cual puede fundarse, entre otras, por la falta de probidad del empleador.

Distinta es la situación del funcionario público. El Estatuto Administrativo establece claramente que si el funcionario estimare ilegal una orden deberá representarla por escrito. Si el superior la reitera en igual forma, aquél deberá cumplirla, quedando exento de toda responsabilidad, la cual recaerá por entero en el superior que hubiere insistido en la orden. Tanto el funcionario que representare la orden, como el superior que la reiterare, enviarán copia de las comunicaciones mencionadas a la jefatura superior correspondiente, dentro de los cinco días siguientes contados desde la fecha de la última de estas comunicaciones.

Al final del día, la denuncia o querella siempre será una decisión personal, o de las personas afectadas, excepto en aquellos casos en que la ley obliga a denunciarlos.

\section{Denuncia de fraudes o irregularidades de carácter corporativo}

Respecto a las cuestiones específicas que encierra los delitos económicos contable-financieros podemos hacer referencia a los consagrados en la Ley 18045/81 sobre Mercado de Valores, por ejemplo. En esa ley se tipifican, entre otras, figuras penales como delitos de falsedad de información, delitos relativos a transacciones de valores ficticias, fraudulentas o con fines ilícitos, delitos relativos a la información privilegiada, delitos de realización de oferta pública de valores por emisores insolventes, y la quiebra fraudulenta del corredor de bolsa o agente de valores. Sin embargo, no existe una tipificación clara respecto a la figura de la manipulación de los estados financieros, responsabilidad de los gerentes y quienes prepararan dicha información en términos de sancionar la alteración, destrucción, mutilación, y falsificación de registros y documentos de carácter contable.

\section{¿Denuncia o confidencialidad? ¿Qué es primero?}

En el ámbito de los negocios y más específicamente en esfera de la información contable-financiero se encuentra una definición en las Normas de Auditoría Generalmente Aceptadas (NAGAS) en la que dice que fraude es un acto intencional por parte de una o más personas de la Administración, encargados del Gobierno Corporativo, empleados o terceros involucrando la utilización del engaño lo cual resulta en una representación incorrecta en estados financieros sometidos a una auditoría.

Como regla general las NAGAS establecen un protocolo básico, pero no determinante, a seguir por los auditores externos respecto a la comunicación de la existencia de una irregularidad o fraude:

a. Si el auditor identifica un fraude u obtiene información que indique la posible existencia de él, lo comunicará oportunamente al nivel adecuado de la Administración (por ejemplo, al gerente general), con el objeto de informar a aquellos con la responsabilidad primaria por la prevención y detección de fraude, de los asuntos pertinentes a sus responsabilidades;

b. No obstante, si el auditor sospecha de un fraude donde se involucra a la Administración, el auditor debiera comunicar estas sospechas a los encargados del Gobierno Corporativo (Directorio, por ejemplo) y analizar con ellos la naturaleza, oportunidad y alcance de los procedimientos de auditoría necesarios para completar la auditoría;

c. Por otro lado, si el auditor ha identificado un fraude, o tiene indicios de que lo haya, determinará si tiene la responsabilidad de informar de ello a un tercero ajeno a la entidad, como lo podría ser una autoridad competente.

Sin embargo, es posible que el deber del auditor de mantener la confidencialidad de la información de su cliente le impida hacerlo. En algunas circunstancias la responsabilidad legal del auditor puede prevalecer sobre el deber de confidencialidad. En determinadas circunstancias el deber de confidencialidad puede quedar invalidado por la normativa legal o los tribunales 
de justicia. Una muestra de esto es lo que el reglamento de sociedades anónimas impone a los auditores externos. En dicho reglamento se impone la obligación al auditor de denunciar a las autoridades judiciales y administrativas competentes, los delitos y las irregularidades o anomalías que a su juicio existieren en la Administración o contabilidad de la sociedad.

En todo caso, como también bien lo señalan las NAGAS, el auditor puede considerar apropiado obtener asesoría legal para determinar la forma más adecuada de proceder según las circunstancias, con el propósito de establecer los pasos necesarios teniendo en cuenta los aspectos de interés público del fraude identificado.

Para el resto de las personas que tienen interés en la sociedad tales como mandos medios, empleados, accionistas, proveedores y otros con carácter de "stakeholder", deberían proceder, como ya se ha señalado, siguiendo los canales de denuncia que estén disponibles en la entidad, recurrir a una autoridad competente o en última instancia, recurrir a la Fiscalía para interponer la denuncia sobre hechos que revisten una acción pública o privada. 